\title{
Increased Binding Activity at an Antioxidant-Responsive Element in the Metallothionein-1 Promoter and Rapid Induction of Metallothionein-1 and -2 in Response to Cerebral Ischemia and Reperfusion
}

\author{
Menno van Lookeren Campagne, Harold Thibodeaux, Nick van Bruggen, Belinda Cairns, and David G. Lowe \\ Department of Cardiovascular Research and Pathology, Genentech Inc., South San Francisco, California 94080
}

\begin{abstract}
Metallothioneins (MTs) are cysteine-rich metal-binding proteins that are potentially involved in zinc homeostasis and free radical scavenging. The expression pattern of MT-1 and the binding activity of various MT-1 promoter elements were investigated after mild focal cerebral ischemia in the rat. Transient focal ischemia was induced by occluding both common carotid arteries and the right middle cerebral artery for $30 \mathrm{~min}$. By the use of real-time quantitative PCR, a 10-fold increase in MT-1 and -2 mRNA levels was found in the cortex $24 \mathrm{hr}$ after reperfusion. In situ hybridization and immunocytochemistry showed a rapid increase in MT-1 and -2 mRNA and MT protein in endothelial cells of microvessels at $6 \mathrm{hr}$ after reperfusion, followed by an increased expression in astrocytes of the infarcted cortex at $24 \mathrm{hr}$ after reperfusion. The early increase in MT expression preceded an increase in cerebral edema measured with T2-weighted mag-
\end{abstract}

netic resonance imaging. Gel shift assays were performed on nuclear extracts prepared from cortices before and at 6 and $24 \mathrm{hr}$ after reperfusion. Increased binding activity was found at an antioxidant/electrophilic response element (ARE) sequence in the MT-1 promoter at $6 \mathrm{hr}$ with a lower and variable binding activity at $24 \mathrm{hr}$ after reperfusion. Constitutive binding activity was found for Sp1 and a metal response element in the MT-1 promoter that did not increase after ischemia and reperfusion. This study suggests a role of ARE-binding proteins in inducing cerebral MT-1 expression and implicates MT-1 as one of the early detoxifying genes in an endogenous defense response to cerebral ischemia and reperfusion.

Key words: antioxidant response element; cerebral ischemia; edema; electrophoretic mobility shift assay; magnetic resonance imaging; metallothionein; promoter
Transient focal cerebral ischemia of 1-2 hr duration induces increased transcription of various genes that either serve to protect cells against the consequences of the insult or activate a cell death pathway (Koistinaho and Hokfelt, 1997). Gene expression is profound in the infarct border zone rather than in the infarct core areas where gene transcription and translation are suppressed and cells die rapidly (Akins et al., 1996). In contrast to focal ischemic insults, global cerebral ischemia elicits a pathology with a clearly delayed time course, and here the gene expression patterns are found in the affected areas before overt pathology (Massa et al., 1996). In the present study we used a model of mild focal cerebral ischemia, in which cell death progresses in a delayed manner $(\mathrm{Du}$ et al., 1996; van Lookeren Campagne et al., 1999b). The extended time course of infarct development in this model may resemble the situation in a subset of patients with acute stroke (Pantano et al., 1999) and allows us to study gene expression patterns that potentially fulfill a role early in infarct development. Among the early response genes are metallothionein-1 and -2 (MT-1 and -2). These genes belong to the phase II-responsive detoxifying genes that convert reactive electrophiles to less toxic and more readily excretable products, thus protecting cells against chemical stresses and carcinogenesis (Prochaska et al., 1985). The coordinate induction of MT- 1 and -2 by heavy metals, hydrogen peroxide, reactive oxygen species, and stress has been well documented (for review, see Palmiter, 1998). As acute response genes, MT-1 and -2 are potential members of a broader class of phase II proteins that serve

Received March 1, 2000; revised April 12, 2000; accepted April 25, 2000.

We would like to thank Simon Williams, Gretchen Frantz, Thuy Nguyen, Pat Sehl, and Jill Schoenfeld for technical assistance and the DNA synthesis group for oligonucleotide synthesis.

Correspondence should be addressed to Dr. Menno van Lookeren Campagne, Department of Immunology, Genentech Inc., mailstop 34, South San Francisco, CA 94080. E-mail: menno@gene.com.

Harold Thibodeaux's present address: Advanced Medicine Inc., South San Francisco, CA 94080.

Copyright (C) 2000 Society for Neuroscience $0270-6474 / 00 / 205200-08 \$ 15.00 / 0$ to protect CNS cells against ischemic injury (van Lookeren Campagne et al., 1999a).

Studying the expression patterns and mechanisms of induction of MT-1 and -2 after cerebral ischemia and reperfusion may broaden our understanding of the endogenous molecular responses triggered by ischemia and reperfusion and help us to develop new therapeutic strategies to treat cerebral ischemia. In the present study we monitored the time course and distribution of MT- 1 and -2 after mild focal ischemia in the rat. In addition, we studied the binding activity of various MT- 1 promoter elements at time points before and after the incidence of selective neuronal necrosis and the formation of cerebral edema.

\section{MATERIALS AND METHODS}

Surgical procedures. All experiments involving the use of animals were approved by Genentech's Animal Care and Use Committee (approved by the American Association for the Accreditation of Laboratory Animal Care). Long-Evans rats (300-330 gm) were deprived of food $24 \mathrm{hr}$ before surgery. Occlusion of the middle cerebral artery (MCA) was performed as described elsewhere (Du et al., 1996; van Lookeren Campagne et al., $1999 b$ ). In short, rats were anesthetized with $2.5 \%$ isoflurane in a mixture of $30 \% \mathrm{O}_{2}$ and $70 \% \mathrm{~N}_{2} \mathrm{O}$. Core temperature was maintained at $37^{\circ} \mathrm{C}$ during and $6 \mathrm{hr}$ after reperfusion using a thermostatically controlled heating blanket (Harvard Instruments, South Natick, MA). The right MCA was exposed via a craniotomy and ligated with a 10-0 suture. Both common carotid arteries were also occluded for the ischemic period. Complete interruption of the blood flow and subsequent reflow was verified directly under the microscope. The cranial window was covered with a piece of webbing, and the skin was sutured after reflow. A separate group of animals $(n=8)$ underwent craniotomy, and a suture was inserted under the MCA but was not tied off (sham operation).

Magnetic resonance imaging. Magnetic resonance imaging (MRI) was performed as described previously (van Lookeren Campagne et al., 1999b) $(n=5-6$ for each time point). In short, rats were reanesthetized with $2 \%$ isoflurane $\left(\mathrm{O}_{2} / \mathrm{N}_{2} \mathrm{O}=30 / 70\right)$ delivered through a face mask. The rats' heads were held rigid in a plastic frame (Applied Neurosciences, Thurso, UK) so that the parietal surface of the skull was horizontal in the magnet and the brain was centered in a volume radio frequency coil operating in quadrature mode (internal diameter, $6 \mathrm{~cm}$ ). The animal core temperature was maintained at $37.0 \pm 0.5^{\circ} \mathrm{C}$ with warm air. The MRI experiments were performed on a 4.7T Varian Unity Inova MR system (Varian Instruments, 


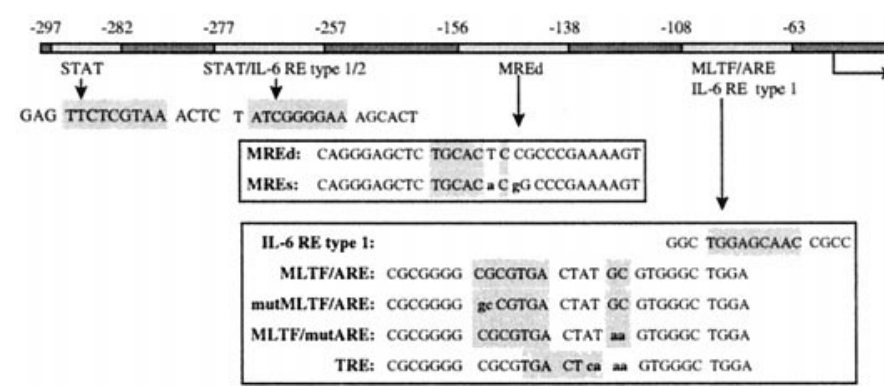

Figure 1. Partial DNA sequence ( -300 to $+20 \mathrm{bp}$ ) of the murine MT-1 promoter showing the putative regulatory elements and their sequences that have been used to design the oligonucleotide probes used for EMSA. The shaded bases indicate the functional core of each element, and the lowercase bases indicate the mutations. ARE. Antioxidant response element; $I L-6 R E$, interleukin-6 response element; $M L T F$, major late transcription factor; MRE, metal response element; mut, mutated; TRE, 12-Otetradecanoylphorbol-13-acetate (TPA) response element.

Palo Alto, CA). T2-weighted MRI was performed on nine contiguous slices, $2 \mathrm{~mm}$ thick, spanning the region of interest. Typical imaging parameters were as follows: echo time, $60 \mathrm{msec}$; repetition time (TR), $1.5 \mathrm{sec}$; field of view, $40 \times 40 \mathrm{~mm}$; matrix, $64 \times 64$; and number of excitations (NEX), 2. T2 relaxation times were obtained from a multiecho-based imaging sequence using eight evenly spaced echoes (echo spacing of 15 msec; TR, 2 sec; NEX, 2; and matrix, $64 \times 64$ ). Image analysis and postprocessing were performed off-line using MRVision software (MRVision Company, Menlo Park, CA). T2 parameter maps were generated from two-parameter fits to monoexponential models. The mean T2 values were measured in the parameter maps from both the ischemic cortex and the contralateral cortex by taking the mean value from three regions of interest that span the lesioned cortex or the contralateral cortex

$m R N A$ expression analysis. At different time points after reperfusion, the entire parietal cortices, including the infarct and peri-infarct regions, were taken out ( $n=5-6$ for each time point) and rapidly frozen in liquid nitrogen, and total RNA was isolated using the RNA Stat procedure (Tel-Test, Friendswood, TX). Real-time TaqMan PCR quantification of MT-1, -2, and -3 mRNA was performed using gene-specific primers and fluorogenic probes and a TaqMan PCR detector (Perkin-Elmer Applied Biosystems, Foster City, CA) as described previously (Schoenfeld et al., 1998). Reagents used were included in the Access reverse transcriptase (RT) PCR kit (Promega, Madison, WI). The primer sets amplified a fragment consisting of base pairs 224-327 of rat MT-1 (GenBank accession number G205382), base pairs 1901-1918, 2182-2247, and 2377-2460 overlapping exon 1,2, and 3, respectively of rat MT-2 (GenBank accession number G205532), and base pairs 211-303 of rat MT-3 (GenBank accession number G4235963). MT-1 mRNA levels were expressed as mRNA equivalents of rat glyceraldehyde-3-phosphate dehydrogenase (GAPDH) mRNA (Schoenfeld et al., 1998).

In situ hybridization. For in situ hybridization, $14 \mu \mathrm{m}$ cryostat sections were cut from fresh-frozen brains of control, sham-operated, and operated animals that had been scanned by MRI shortly before death $(n=3$ for each time point). Sections were fixed in $4 \%$ paraformaldehyde and dried before in situ hybridization. Sense and antisense riboprobes were transcribed from PCR products obtained from rat brain cDNA in the presence of ${ }^{33}$ P]UTP (Amersham, Buckinghamshire, UK). The cDNA sequences used to transcribe probes consisted of base pairs $44-375$ of rat MT-1 (GenBank accession number g205382), base pairs 1905-1918, 2182-2247, and 2377-2449 overlapping exon 1,2, and 3, respectively of rat MT-2 (GenBank accession number g205532), and base pairs 17-321 of rat MT-3 (GenBank accession number g4235963). Sections were exposed to autoradiography film (Amersham Hyperfilm; Amersham) for 1 week and subsequently dipped in NTB-2 emulsion (Eastman Kodak, Rochester, NY), exposed for 3 weeks, and counterstained with hematoxylin and eosin.

Immunocytochemistry. At different time points after MCA occlusion, animals were anesthetized with sodium pentobarbital and perfused transcardially with $4 \%$ paraformaldehyde dissolved in $0.1 \mathrm{M} \mathrm{PBS}(n=3$ for each time point). Brains were subsequently embedded in paraffin wax, and $7 \mu \mathrm{m}$ sections were stained using a monoclonal antibody to metallothionein (E9; Dako, Glostrup, Denmark) as described elsewhere (van Lookeren Campagne et al., 1999a). Sections were counterstained with hematoxylin and eosin.

Preparation of nuclear extracts. Nuclear extracts were prepared with modifications of the method of Dignam et al. (1983) $(n=4$ for each condition). Rat ipsilateral parietal cortices were dissected from control brain and at 6 and $24 \mathrm{hr}$ after MCA occlusion and reperfusion. The cortices were homogenized using a glass homogenizer (Kontes, Vineland, $\mathrm{NJ}$ ) in $3 \mathrm{ml}$ of cell lysis buffer consisting of $10 \mathrm{~mm}$ HEPES, $1.5 \mathrm{mM} \mathrm{MgCl}_{2}$, $10 \mathrm{~mm} \mathrm{KCl}, 0.5 \mathrm{~mm}$ DTT, $\mathrm{pH} \mathrm{7.9}$, and the following protease/phosphatase inhibitors: $0.2 \mathrm{~mm}$ dimethylsulfonyl fluoride, $10 \mu \mathrm{g} / \mathrm{ml}$ aprotinin, $10 \mu \mathrm{g} / \mathrm{ml}$ leupeptin, $1.5 \mu \mathrm{g} / \mathrm{ml}$ pepastatin, $1 \mu \mathrm{g} / \mathrm{ml}$ phosphoramidon, and $1 \mathrm{~mm}$ $\mathrm{Na}_{3} \mathrm{VO}_{4}$ (all from Boehringer Mannheim, Mannheim, Germany). After 15
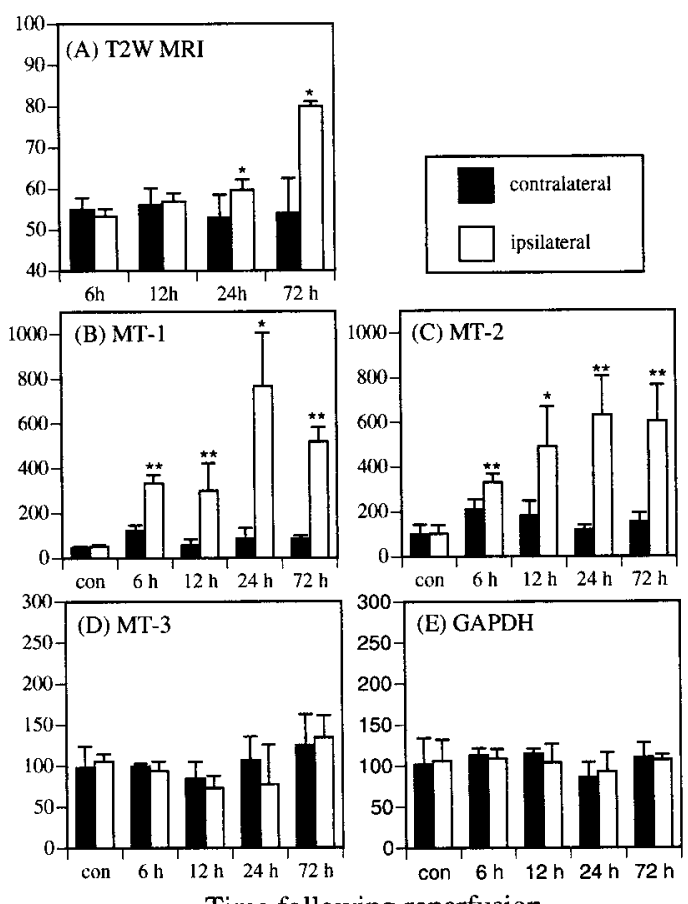

Time following reperfusion

Figure 2. Increased expression of MT-1 and -2 mRNA in the ischemic cortex precedes the formation of cerebral edema. $A$, T2 relaxation time increased in the ipsilateral cerebral cortex by $24 \mathrm{hr}$ and further increased at $72 \mathrm{hr}$ after reperfusion. $B, C$, mRNA levels of both MT-1 $(B)$ and MT-2 $(C)$ were significantly increased in the ipsilateral (ischemic) cerebral cortex $6 \mathrm{hr}$ after reperfusion and peaked at $24 \mathrm{hr}$ after reperfusion. $D, E$, In contrast, no significant changes in MT-3 or GAPDH mRNA were found. Values are expressed as the mean \pm SD of samples obtained from five to six animals (*, $p<0.05 ;{ }^{* *}, p<0.01$, paired $t$ test). a.u., Arbitrary units; con, control; $T_{2} W, \mathrm{~T}_{2}$-weighted.

min on ice, $180 \mu \mathrm{l}$ of a solution of $10 \%$ Nonidet P-40 (Fluka, Natick, MA) was added, and the homogenate was vortexed for $10 \mathrm{sec}$ and centrifuged at $1500 \times g$ for $5 \mathrm{~min}$ at $4^{\circ} \mathrm{C}$. The pellet was gently resuspended in $0.5 \mathrm{ml}$ of cell lysis buffer. Under continuous agitation, $750 \mu \mathrm{l}$ of $20 \mathrm{mM}$ HEPES, $\mathrm{pH}$ $7.9,1.5 \mathrm{mM} \mathrm{MgCl}_{2}, 400 \mathrm{mM} \mathrm{KCl}_{2}, 0.5 \mathrm{~mm}$ DTT, and the protease inhibitors was added dropwise. The homogenate was gently rocked at $4^{\circ} \mathrm{C}$ for $15 \mathrm{~min}$. Nuclear remains were spun down by centrifugation at $14,000 \times g$ for 30 min at $4^{\circ} \mathrm{C}$, and the supernatant was collected and frozen at $-70^{\circ} \mathrm{C}$.

Electrophoretic mobility shift assay. Nuclear proteins $(5 \mu \mathrm{g})$ were incubated in binding-reaction buffer, $\mathrm{pH} 7.9$, containing $12 \mathrm{mM}$ HEPES, $60 \mathrm{mM}$ $\mathrm{KCl}, 0.5 \mathrm{~mm} \mathrm{DTT}, 12 \%$ (v/v) glycerol, $5 \mathrm{~mm} \mathrm{MgCl}_{2}, 0.4 \mu \mathrm{g}$ of poly $\mathrm{dI}-\mathrm{dC}$, and $1.75 \mathrm{pmol}$ of end-labeled double-stranded oligonucleotide $(30,000$ $\mathrm{cpm} / \mathrm{pmol}$ ) in a total volume of $10 \mu \mathrm{l}$ for $30 \mathrm{~min}$. In binding-site competition experiments, a 200-fold molar excess of unlabeled oligonucleotide was added to the reaction mixture. In antibody competition experiments, the following antibodies were added to the reaction mixture: anti-signal transducer and activator of transcription (STAT)-1 and STAT-3 (E-23 $s c-346$ and C-20 sc-48) and anti-c-jun/ap1 (sc-45X; Santa Cruz Biotechnology, Santa Cruz, CA). The oligonucleotide sequences used for electrophoretic mobility shift assays (EMSA) are shown in Figure 1. The design of the oligonucleotides is based on the following references: MREd $(\mathrm{Cu}-$ lotta and Hamer, 1989), MREs (Radtke et al., 1993), Sp1 (Briggs et al., 1986), MLTF/ARE (Dalton et al., 1994), mutMLTF/ARE (Carthew et al., 1987), MLTF/mutARE (Nguyen et al., 1994), TRE (Angel et al., 1987), STAT (MT-297) and STAT (MT-277) (Wegenka et al., 1993; Lee et al., 1999), and IL-6 RE type1/type2 (IL-6 RE 1/2) and IL-6 RE type1 (IL-6 RE 1) (Kasutani et al., 1998). The activator protein-1 (AP1) oligonucleotide was obtained from Promega. Reaction mixtures were run on a $6 \%$ Tris/glycine gel (Novex, San Diego, CA), dried, and apposed to a PhosphorImaging screen (Molecular Dynamics, Sunnyvale, CA). Screens were analyzed with a PhosphorImager (Molecular Dynamics) at $100 \mu \mathrm{m}$ in plane resolution. Relative binding activities were quantified by determining pixel densities using ImageQuant software (Molecular Dynamics).

Statistical analysis. The data are expressed as the mean \pm SD. Differences in T2 relaxation time values and in mRNA levels in the ipsilateral compared with the contralateral hemisphere were tested for significance using the paired $t$ test. Changes in promoter-binding activity in ischemic versus control cortical lysates were determined using the two-tailed Student's $t$ test. 
T2W MRI

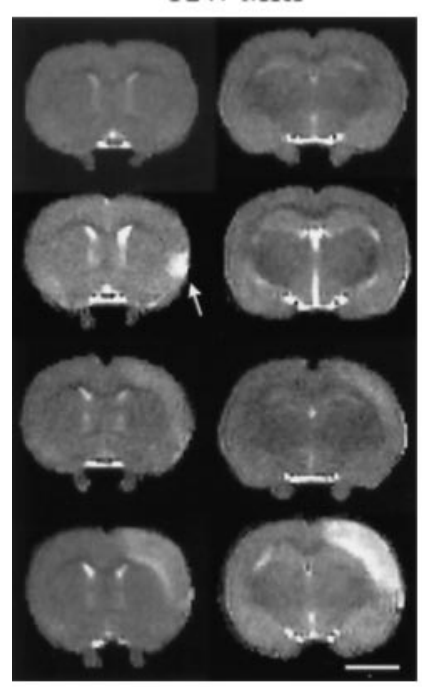

MT-1

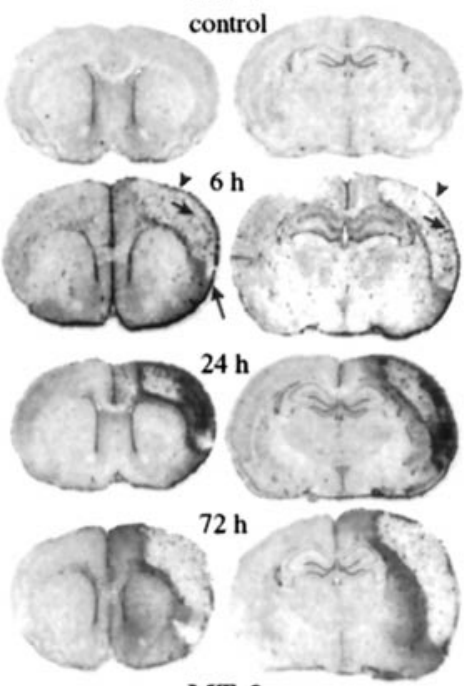

MT-3

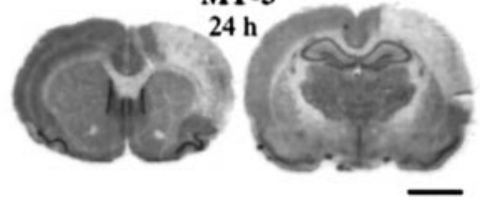

Figure 3. Increased expression of MT-1 mRNA in an area in which cerebral edema develops. Anatomical comparison of changes in T2 relaxation time visualized in $\mathrm{T} 2$ parameter maps (below $T_{2} W M R I$ ) with changes in MT-1 and -3 mRNA expression (below MT-1). During the first $24 \mathrm{hr}$ after reperfusion, expression of MT-1 transcripts transiently increased, preceding the development of cerebral edema at $72 \mathrm{hr}$ after reperfusion. At this time point, MT-1 expression shifts from being localized primarily in the cortical infarct to localization in an area bordering the ischemic infarct. In contrast to MT-1, MT-3 expression decreased in the infarcted cortex by 24 hr. High expression of MT-1 is indicated with arrowheads in the pia mater and with short arrows in brain microvessels at $6 \mathrm{hr}$ after reperfusion. The long arrows in the $6 \mathrm{hr}$ images show edema formation around the surgical wound. Scale bars, $3.5 \mathrm{~mm}$.

\section{RESULTS}

\section{Increased expression of MT-1 mRNA and protein in microvascular endothelial cells and glial cells occurs before the formation of cerebral edema}

Thirty minutes of MCA occlusion induces a delayed infarction that establishes between 12 and $24 \mathrm{hr}$ after reperfusion (Du et al., 1996; van Lookeren Campagne et al., 1999b). The tissue changes after MCA occlusion and reperf usion can be noninvasively monitored by T2-weighted MRI that measures changes in the T2 relaxation time indicative of the formation of cerebral edema. A significant increase in $\mathrm{T} 2$ relaxation time in the ipsilateral cortex was not found until $24 \mathrm{hr}$ after reperfusion (Fig. $2 A$ ). Changes in the T2 relaxation time were compared with changes in MT gene expression using real-time RT-PCR on the cortices of previously imaged animals. A significant 2.5-fold increase in the expression of MT-1 mRNA was found at $6 \mathrm{hr}$ and peaked with a 10-fold increase of baseline levels at $24 \mathrm{hr}$ (Fig. 2B). The regulation of MT-2 mRNA levels was similar to that of MT-1 with a 5-fold increase at $24 \mathrm{hr}$ (Fig. $2 C$ ). In contrast, there were no significant changes in MT-3 mRNA levels or in GAPDH mRNA levels relative to total RNA content in cortex homogenates obtained at any time point after reperfusion (Fig. 2D,E).

T2 parameter maps and in situ hybridization autoradiograms (Fig. 3) obtained from the same animals were compared to assess how the temporal pattern of MT-1 expression relates to changes in the $\mathrm{T} 2$ relaxation time of the cortical tissue. By the use of sense cRNA probes, no specific hybridization was observed (results not shown). Using antisense cRNA probes induction of MT-1 mRNA in endothelial cells of cerebral microvessels and the pia mater of
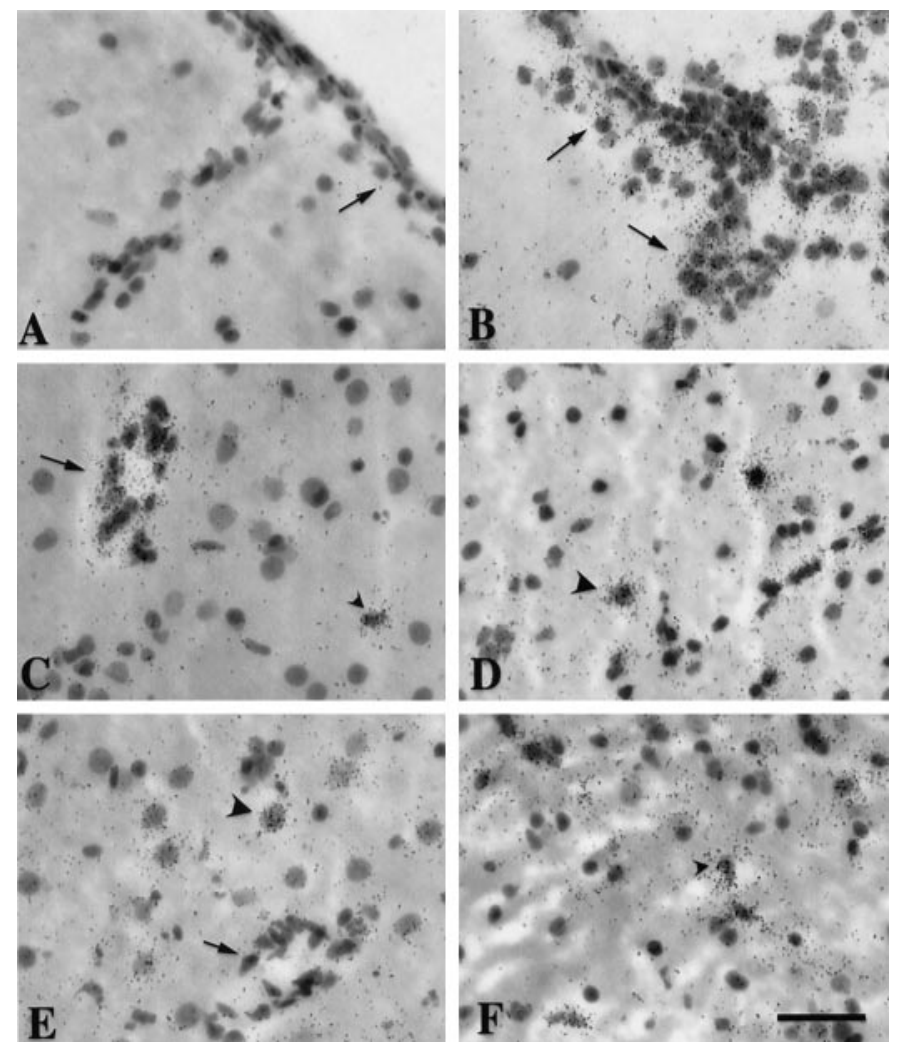

Figure 4. MT-1 mRNA is rapidly induced in brain microvessels and the pia mater after ischemia and reperfusion. $A$, In situ hybridization microscopy shows low transcript levels in cortical microvessels and the pia mater of a control animal (arrow). B, C, Clear induction of MT-1 was found at $6 \mathrm{hr}$ in the pia mater and cerebral microvessels (arrows in $B, C$, respectively) as well as in some cells with oval, small nuclei (small arrowhead in $C$ ). $D, E$, At 24 hr after reperfusion, MT-1 mRNA increased in cells of the cortex with round large nuclei (large arrowheads in $D, E$ ) and decreased in endothelial cells of cerebral microvessels (arrow in $E$ ). $F$, Seventy two hours after reperfusion, MT-1 mRNA was decreased in the infarct zone but increased in cells with oval nuclei in the infarct border areas (small arrowhead). Scale bar, $50 \mu \mathrm{m}$; all images were taken at a similar magnification.

the ipsilateral cortex was found at $6 \mathrm{hr}$ after reperfusion, a time point at which no detectable cerebral edema was evident from the T2 parameter maps and the cells appeared morphologically unaffected (Fig. 3) (see also van Lookeren Campagne et al., 1999b). In $20 \%$ of the operated and sham-operated animals, local formation of edema was found at the site of the cranial window where the MCA was tied off, but this area was remote from that where vascular expression of MT-1 was found (Fig. 3). The pattern of MT-2 mRNA expression was similar to that of MT-1 (results not shown). At $24 \mathrm{hr}$ after reperfusion, T2 relaxation time had increased in the ipsilateral parietal cortex and partly overlapped with MT-1 mRNA expression. The part of the cortex with the highest T2 values showed a decrease in the expression of MT- 1 mRNA. In contrast to MT-1 and -2, MT-3 mRNA expression was reduced in the ipsilateral cortex $24 \mathrm{hr}$ after reperfusion. By $72 \mathrm{hr}$ after reperfusion, T2 relaxation time had significantly increased $(51.3 \pm 1.5$ contralateral and $79.0 \pm 6.2$ ipsilateral, mean $\pm \mathrm{SD} ; p<0.01)$ in the ischemic area in the cortex that had developed into an area of confluent necrosis (results not shown). Expression of MT-1 was reduced in all cell types in the infarcted cortex but had increased in cells bordering the corpus callosum. Cortical tissue obtained at 24 hr after sham operation showed a similar MT-1 and -3 mRNA distribution pattern compared with that of nonoperated controls (results not shown).

In situ hybridization microscopy was applied to study the cellular source of MT-1 expression. Control cortical tissue (Fig. 4A) showed a low hybridization signal in epithelial cells of the pia mater 


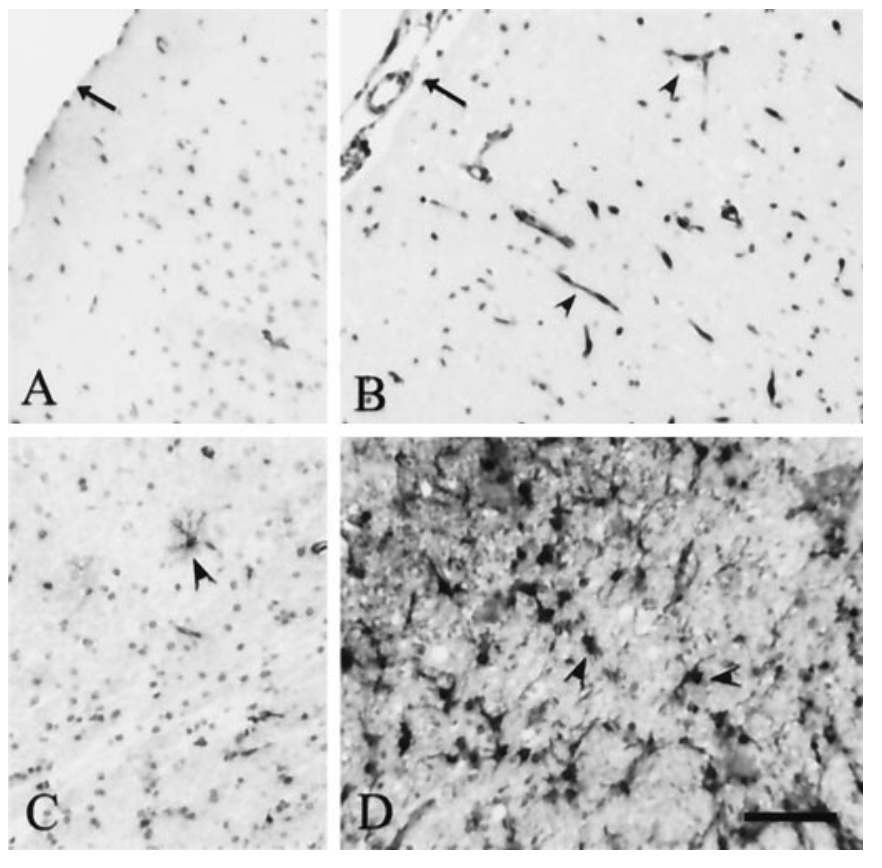

Figure 5. MT protein is highly expressed in brain microvessels and glial cells of the ipsilateral parietal cortex at 6 and $24 \mathrm{hr}$ after reperfusion. $A, C$, Immunocytochemistry shows the absence of staining in most of the cells of the control nonischemic parietal cortex except for a low expression of MT in the pia mater (arrow in $A$ ) and some glia cells (arrowhead in $C$ ). $B$, Six hours after reperfusion, MT protein is increased in the nuclei and cytoplasm of endothelial cells of cerebral microvessels (arrowheads) and the epithelial cells of the pia mater (arrow). D, At $24 \mathrm{hr}$ after reperfusion, high levels of MT protein were expressed in the nuclei and processes of astrocytes in the inner cortical layers, bordering the corpus callosum (arrowheads). Scale bar, $50 \mu \mathrm{m}$; all images were taken at a similar magnification.

and in endothelial cells of cerebral microvessels in the cortex. Six hours after reperfusion, MT-1 mRNA had increased in the pia mater and arachnoid (Fig. 4B, arrows) and in microvascular endothelial cells (Fig. 4C, arrow) of the ischemic cortex. Some cells with oval small-sized nuclei, indicative of astrocytes (Bass et al., 1971), showed selective expression of MT-1 mRNA (Fig. 4C, small arrowhead). At $24 \mathrm{hr}$ after ischemia and reperfusion, mRNA levels were highly increased in cells with round large nuclei, presumably neurons (Bass et al., 1971), and oval small nuclei but were reduced in cerebral microvessels (Fig. 4D,E). Three days after reperfusion, MT-1 was reduced in the infarct area, but increased levels of expression were found in cells with oval small-sized nuclei bordering the infarct zone (Fig. $4 F$ ). In both the in situ hybridization autoradiograms and in the microscopic images, the distribution of MT-1 and -2 was identical (results not shown).

We further studied whether MT protein was induced after cerebral ischemia and whether this corresponded to the expression of MT-1 and -2 mRNA. The monoclonal antibody used in this study detects both MT-1 and -2, and the antigen therefore is referred to as MT. In the control cortex, MT staining was low in vascular endothelial cells and the pia mater of the outer cortical layers (Fig. 5A) and was present in some glial cells of the inner cortical layers (Fig. $5 C$ ). MT immunoreactivity was clearly induced in cerebral microvessels of the ipsilateral cortex at $6 \mathrm{hr}$ after reperfusion (Fig. 5B) and further increased in cells of the inner cortical layer bordering the corpus callosum at $24 \mathrm{hr}$ after reperfusion (Fig. 5D), corresponding with the expression of MT-1 mRNA. Labeling of adjacent sections with GFAP antibodies showed that MT protein was predominantly found in astrocytes (results not shown), confirming previous observations (Nishimura et al., 1992). Nuclei of neurons were only occasionally labeled at 24 hr after reperfusion (results not shown).

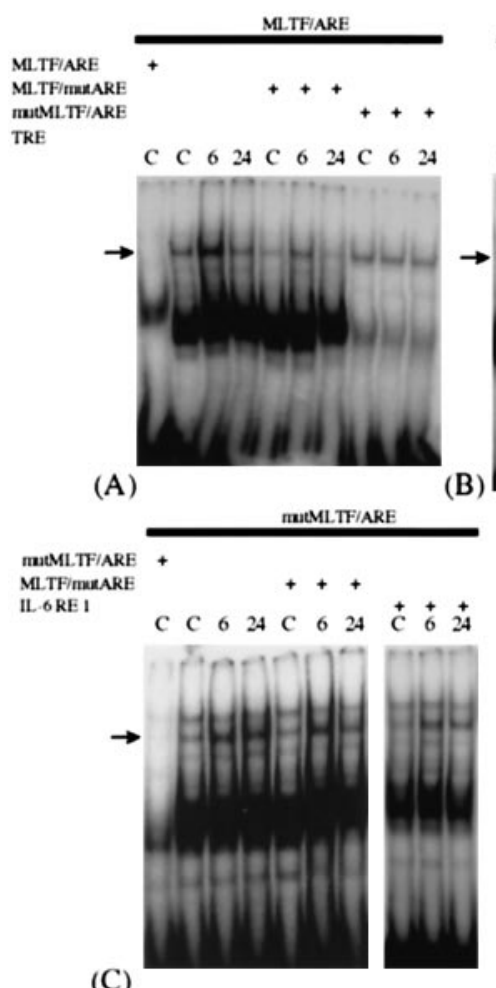

(C)

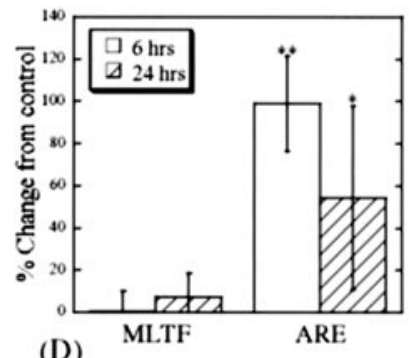

(D)
Figure 6. Detection of an increased ARE-binding activity in nuclear extracts from ischemic cortices. Nuclear extracts were isolated from control cortices $(C)$ and from cortices obtained at $6 \mathrm{hr}(6)$ and $24 \mathrm{hr}(24)$ after reperfusion. Panel $A$, EMSA was performed with a ${ }^{32} \mathrm{P}$-labeled probe containing both the intact MLTF and ARE sequences. Panel $B$, EMSA was performed with a ${ }^{32} \mathrm{P}$-labeled MLTF/mutARE probe. Panel $C$, EMSA was performed with a ${ }^{32} \mathrm{P}$-labeled probe containing mutMLTF/ARE. Where indicated $(+)$, the binding reaction contained a 200 -fold molar excess of the specified unlabeled oligonucleotide. The arrows point to a specific proteinDNA complex. Panel D, Graphic representation of the relative changes in the binding activity of MLTF and ARE sequences at 6 and $24 \mathrm{hr}$ of reperfusion compared with that of control, nonoperated animals is shown. Values are expressed as the mean $\pm \mathrm{SD}(n=4 ; * p<0.05 ; * * p<0.01$, Student's $t$ test).

\section{Ischemia or reperfusion induces increased antioxidant- responsive element-binding activity}

Our next approach was aimed at finding out how MT-1 expression is regulated after transient focal cerebral ischemia. Using nuclear extracts from control cortical tissue and cortices obtained at 6 and $24 \mathrm{hr}$ after reperfusion, we performed EMSA. The oligonucleotides represent sequences in the promoter region of $\mathrm{MT}$ genes that have been shown previously to function as cis- and trans-regulatory elements of MT-1 gene expression (see also Fig. 1). These included the MLTF/ARE element (Dalton et al., 1994), a metal response element MREd (Culotta and Hamer, 1989), the IL-6 regulatory element, and STAT-binding elements (Wegenka et al., 1993; Kasutani et al., 1998; Lee et al., 1999). We choose to design the oligonucleotides on the basis of the extensively characterized mouse MT-1 promoter sequence (Carthew et al., 1987; Culotta and Hamer, 1989; Dalton et al., 1994). Comparison of the mouse and rat MT-1 promoter sequences shows that the functional core of the analyzed promoter elements is conserved in both species (Andersen et al., 1986; Dalton et al., 1994).

A specific complex was detected by EMSA using the mouse MLTF/ARE oligonucleotide and rat cortical nuclear extracts (Fig. 6A). Complex formation was abolished by a 200 -fold molar excess of unlabeled oligonucleotide. In repeated experiments, a transient increase in complex formation was detected at $6 \mathrm{hr}$ after occlusion and reperfusion. Mutation of the two functionally important terminal bases (GC) of the ARE consensus sequence (GTGACnnnGC) (Nguyen et al., 1994; Favreau and 


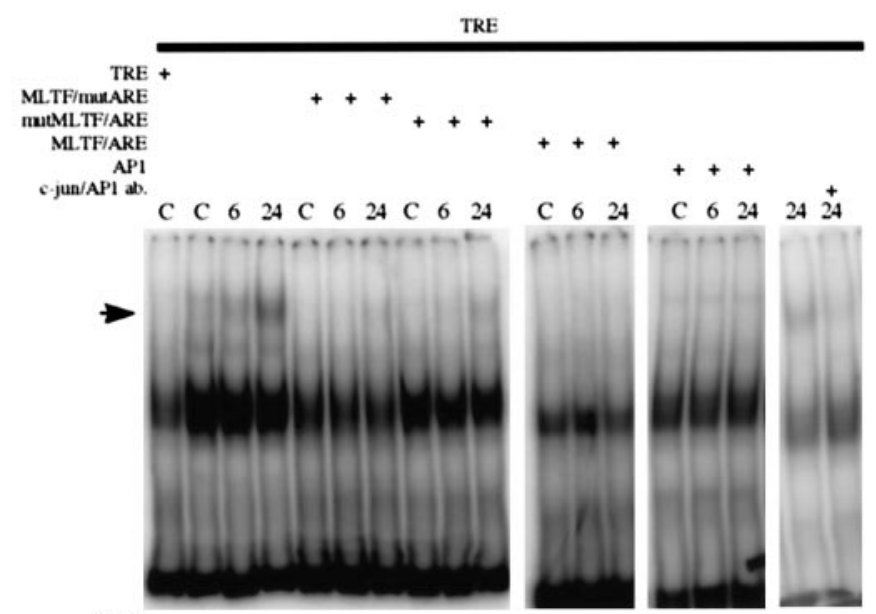

(A)

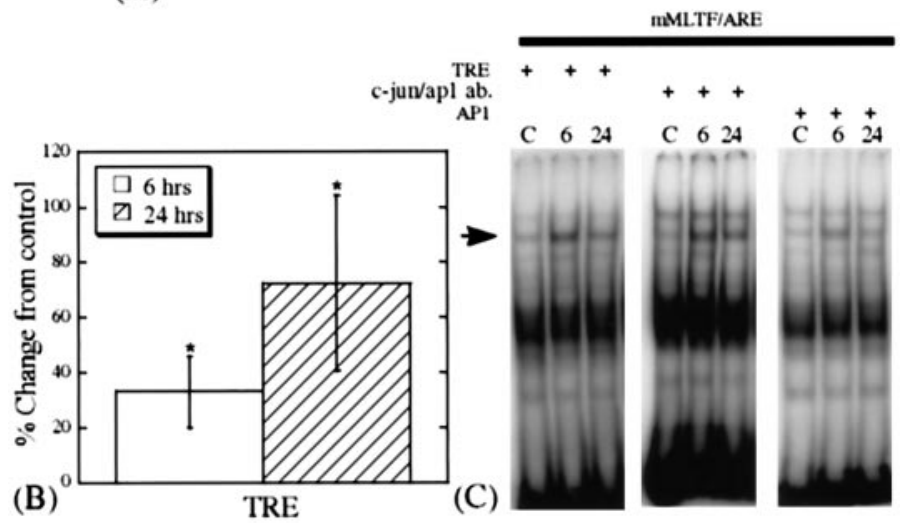

Figure 7. Increased binding activity of a TRE in nuclear extracts from ischemic cortical tissue obtained at 6 and $24 \mathrm{hr}$ after reperfusion. Panel $A$, Nuclear extracts from control cortex (C) and $6 \mathrm{hr}(6)$ and $24 \mathrm{hr}(24)$ postischemic cortex were incubated with a ${ }^{32} \mathrm{P}$-labeled oligonucleotide containing the TRE sequence of the MT-1 promoter. Where indicated (+), the binding reaction contained a 200 -fold molar excess of the indicated unlabeled oligonucleotide. Panel B, The graph depicts changes in TRE-binding activity in cortical nuclear extracts of rats at 6 and $24 \mathrm{hr}$ after reperfusion compared with that of control nonoperated animals. Values are expressed as the mean $\pm \mathrm{SD}(n=4 ; *$, significantly different from binding activity in control lysates, $p<0.01$, Student's $t$ test). Panel $C$, Binding activity of mutMLTF/ARE ( $m M L T F / A R E)$ was not competed for by a 200 -fold molar excess of the oligonucleotides encoding TRE, AP1, or an antibody against the $c$-jun family (c-jun/ap1 ab.) that was added to the binding reaction shortly after addition of the ${ }^{32} \mathrm{P}$-labeled probe. Arrows indicate the position of a specific complex.

Pickett, 1995) in the competitor oligonucleotide (MLTF/ mutARE) resulted in a protein-DNA-binding complex that increased at $6 \mathrm{hr}$ after occlusion. In contrast, mutation of the functionally important (Carthew et al., 1987) first three bases of the MLTF-binding site (CGCGTGAC) in the competitor oligonucleotide (mutMLTF/ARE) resulted in a protein-DNA complex with no changes in binding activity at any time after reperfusion (Fig. 6A). We further tested the specificity of the complexes by using the mutated oligos as probes. Binding studies with labeled MLTF/mutARE resulted in two complexes, only one of which (the faster-migrating complex) could be competed for by adding an excess of unlabeled homologous competitor oligonucleotide (Fig. 6B). No changes in MLTF/mutAREbinding activity were observed after ischemia and 6 or $24 \mathrm{hr}$ of reperfusion (Fig. 6B,D). EMSA using mutMLTF/ARE as a probe resulted in two complexes, only one of which (the faster migrating) could be inhibited by an excess of unlabeled homologous oligonucleotide (Fig. $6 C$ ). Binding of the faster-migrating complex was significantly increased to twofold of control levels at $6 \mathrm{hr}$ after occlusion (Fig. 6C,D) and was not competed for by excess unlabeled MLTF/mutARE oligonucleotide and IL-6 RE 1.
TRE binding is increased at $24 \mathrm{hr}$ after stroke but does not participate in ARE-binding activity

Although AP1 has been shown to bind to AREs (Jaiswal, 1994), several studies suggest that ARE function is not mediated by AP1 (Nguyen et al., 1994; Prestera and Talalay, 1995; Yoshioka et al., 1995). AP1-binding activity in the nuclear extracts after ischemia and reperfusion and its possible contribution to the ARE complex were examined by studying the binding activity of a consensus AP1 element (TGACTCA), also known as TRE. This element has been shown to be responsible for the binding of AP1 complexes to ARE sequences in the MT-1 and $\gamma$ glutamylcysteine synthetase (GCS) promoters (Mulcahy et al., 1997; Wild et al., 1998) (see also Fig. 1). A TRE-specific complex was detected in control extracts and increased to twofold of baseline levels at $24 \mathrm{hr}$ after reperfusion (Fig. $7 A, B)$. MLTF/mutARE and mutMLTF/ARE probes partially competed for TRE-binding activity and diminished complex formation by $\sim 40 \%$, whereas the nonmutated MLTF/ARE competitor oligonucleotide completely inhibited the binding of TRE. An AP1 consensus oligonucleotide sequence fully inhibited the formation of the TRE complex, and an antibody against the c-jun family, which blocks the binding of c-jun-containing AP1 complexes, inhibited complex formation by $>80 \%$ (Fig. $7 A$ ). In contrast, the TRE consensus oligonucleotide, the AP1/c-jun antibody, and the AP1 consensus oligonucleotide did not interfere with the increased mutMLTF/ARE binding after ischemia and reperfusion (Fig. 7C), indicating that ARE binding does not involve AP1 or TRE as a major binding activity in the MT-1 promoter.

\section{Constitutive binding of MREd, Sp1, MREs, STAT, and IL- 6 but no changes in binding activities after ischemia and reperfusion}

To examine whether other complexes might influence MT-1 transcription after cerebral ischemia and reperfusion, we studied the binding activity of an MRE in the MT-1 promoter region. MREd is bound by two transcription factors, metal transcription factor-1 (MTF-1) and Sp1 (Westin and Schaffner, 1988). MTF-1-binding activity has been shown to be activated in response to oxidative stress (Murphy et al., 1999) and therefore may mediate MT-1 transcription after cerebral ischemia and reperfusion. Two complexes were detected by EMSA using the mouse MREd oligonucleotide as a probe (Fig. 8). The slower-migrating complex disappeared in the presence of excess unlabeled Sp1 oligonucleotide, whereas the faster-migrating complex disappeared in the presence of excess consensus oligonucleotide MREs, which is a strong MTF1-binding site but does not bind Sp1 (Radtke et al., 1993; Dalton et al., 1996). MRE-binding activity decreased at 6 and $24 \mathrm{hr}$ after reperfusion (Fig. 8; significant at $6 \mathrm{hr}$ ). Sp1-binding activity did not significantly change at any time point after reperfusion.

Both STAT and IL-6 have been shown to induce MT transcription (Kasutani et al., 1998; Lee et al., 1999). The MT-1 promoter contains an upstream STAT site at position -297 relative to the transcriptional start site, a combined IL-6 receptor element type 1/type 2, a STAT site at the upstream positions -277 to -257 , and a downstream IL-6 RE type 1 element at positions -80 to -60 relative to the transcriptional start site (Kasutani et al., 1998; Lee et al., 1999) (see also Fig. 1). Constitutive binding activity was found for all three sites (Fig. 9) but did not change after ischemia and reperfusion. Antibody to STAT3, but not to STAT1, supershifted the protein-DNA complex formed at the upstream STAT site (Fig. 9A) and at the combined STAT/IL-6 RE 1/2 site (Fig. 9B). Specific binding activity at both sites was competed for by excess homologous oligonucleotide.

\section{DISCUSSION}

This study for the first time describes the rapid induction of MT-1 in brain microvascular endothelial cells and astrocytes after mild cerebral ischemia. MT-1 has been shown previously to bind zinc (Liu et al., 1991; Liu et al., 1995). In addition, MT-1 has been proposed to scavenge oxygen free radicals in vitro (Thornalley and Vasak, 1985). MT-1 may thus attenuate the toxicity of both zinc 


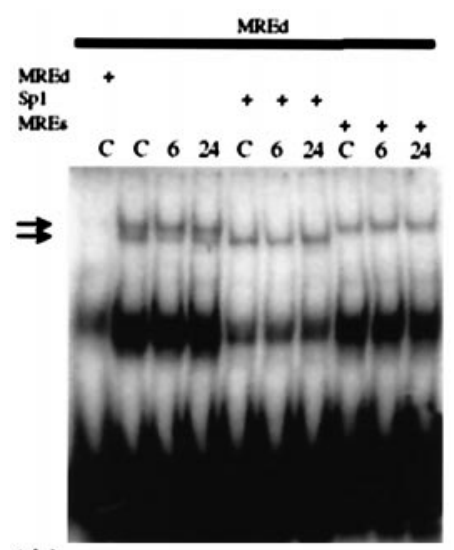

(A)

(B)

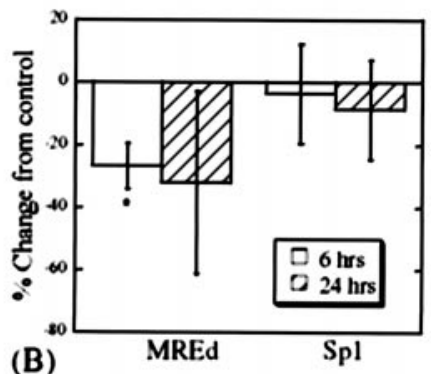

Figure 8. Constitutive binding of MTF-1 and Sp1 in nuclear extracts from control and postischemic cortices. $A$, Nuclear extracts from control cortex $(C)$ and cortices obtained at $6 \mathrm{hr}(6)$ and $24 \mathrm{hr} \mathrm{(24)} \mathrm{after} \mathrm{reperfusion} \mathrm{were}$ incubated with a ${ }^{32} \mathrm{P}$-labeled oligonucleotide containing MREd, a metalresponsive element sequence of the MT-1 promoter that binds MTF-1. Where indicated $(+)$, the binding reaction contained a 200 -fold molar excess of the unlabeled oligonucleotides coding for MREd, the Sp1-binding element, and MREs. The positions of the protein-DNA complexes are indicated by arrows (Sp1, top arrow; MTF-1, bottom arrow). B, Graphic representation of the relative changes in binding activity in nuclear extracts at 6 and $24 \mathrm{hr}$ after reperfusion compared with that of control nonoperated animals is shown. Values are expressed as the mean $\pm \operatorname{SD}(n=4$; *, significantly different from binding activity in control lysates, $p<0.01$, Student's $t$ test).

and free radicals that are considered important components contributing to the pathophysiology of stroke (Chan, 1996; Koh et al., 1996). Taken together, the rapid induction of MT-1 mRNA and protein in microvascular endothelial cells and glial cells before the peak formation of cerebral edema may implicate a role for MT-1 in blood-brain barrier integrity after cerebral ischemia. Supporting evidence of a cerebral protective role of MT-1 has been found in our previous study. Here, mice that overexpress MT-1 protein in brain microvessels, astrocytes, and neurons showed increased protection against cerebral edema and sparing of cortical motor function (van Lookeren Campagne et al., 1999a). In addition, a recent study has shown that mice lacking MT-1 and -2 display an altered immune response and delayed tissue recovery after cortical freeze injury (Penkowa et al., 1999), and a role of MT-1 in regulating inflammatory mediators like IL-6 has been proposed (Carrasco et al., 1998). Whether the immune-regulatory properties, the zincbinding properties, the free radical-scavenging properties, or the redox properties of MTs play an important role in protection against ischemia-reperfusion still is unclear, but the present and previous studies suggest that MT-1 may act as an acute response gene with a protective function.

Both the ARE (also named electrophilic response element) and MLTF (also named upstream stimulatory factor) binding sites in the MT- 1 promoter have been extensively characterized in previous studies using cell lines. Promoter constructs have shown the involvement of various response elements, including MLTF and ARE, in a response to oxidative stress induced by tertbutylhydroquinone (Carthew et al., 1987; Dalton et al., 1994; Nguyen et al., 1994; Dalton et al., 1996; Ahlgren-Beckendorf et al., 1999), but to date activation of these response elements to ischemia and reperfusion has not been studied. AREs are regulatory sequences found on promoters of several phase II detoxification genes that are inducible by xenobiotics and antioxidants. Included in the group with ARE consensus sequences are ferritin-L, $\gamma \mathrm{GCS}$, $\mathrm{NAD}(\mathrm{P}) \mathrm{H}$ :quinone oxidoreductase 1 (NQO1), and glutathione $S$-transferase (GST) (Xie et al., 1995). In a recent study, the role of ARE/MLTF-binding sites in mediating oxidative stress-induced NQO1 and GST expression in astroglia cells has been demonstrated (Ahlgren-Beckendorf et al., 1999). All previous studies

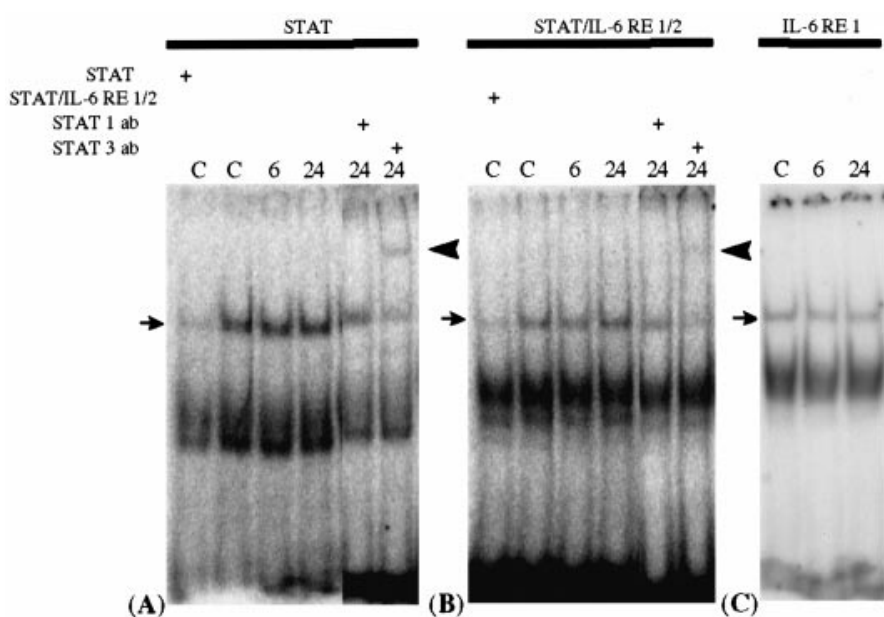

Figure 9. Constitutive binding of STAT and IL-6 response elements in the MT-1 promoter and the absence of changes after reperfusion. Nuclear extracts from control cortex $(C)$ and cortices obtained at $6 \mathrm{hr}(6)$ and $24 \mathrm{hr}$ (24) after reperfusion were incubated with a ${ }^{32} \mathrm{P}$-labeled oligonucleotide containing an upstream STAT response element (STAT; panel $A)$, a combined STAT and upstream IL-6 response element (STAT/IL-6 RE 1/2; panel $B)$, and a downstream IL-6 response element (IL-6 RE 1 ; panel $C)$. Where indicated $(+)$, the binding reaction contained a 200 -fold molar excess of the unlabeled oligonucleotides. STAT $1 a b$ and STAT $3 a b$ denote addition of antibody to the binding reaction shortly after addition of the ${ }^{32} \mathrm{P}$-labeled probe. The positions of the protein-DNA complexes are indicated with arrows; the positions of the supershifted complexes are indicated with arrowheads.

describe the ARE as a composite regulatory site, where multiple transcription factors interact (Wasserman and Fahl, 1997). In the present study, the increased mutMLTF/ARE-binding activity did not involve an AP1 complex as shown by competition and supershift studies using competitor TRE oligonucleotides and AP1 antibodies. Although TRE and AP1 do not compete for mutMLTF/ ARE-binding activities, MLTF/ARE oligonucleotides compete with increased TRE-binding activities after cerebral ischemia, indicating that TRE- and ARE-binding elements may cooperate in MT-1 transcriptional regulation. However, on the basis of the results of this and previous studies, it seems unlikely that AP1/TRE complexes are involved in MT-1 regulation after cerebral ischemia. First, the time course of mutMLTF/ARE-binding activity differed from that of TRE, the former transiently increasing at $6 \mathrm{hr}$ after reperfusion and the latter increasing to $24 \mathrm{hr}$ after reperfusion. Second, the expression and activation of the AP1 proteins Fos and Jun after cerebral ischemia have primarily been found in neurons rather than in astrocytes and vascular endothelial cells (for review, see Koistinaho and Hokfelt, 1997), indicating that AP1 complexes are not involved in MT-1 transcriptional regulation in nonneuronal cells after ischemia and reperfusion. The transient increase in mutMLTF/ARE-binding activity in our study correlated with MT-1 mRNA and protein expression in brain microvessels and pia mater but not in total brain tissue homogenates in which MT-1 mRNA levels peaked at $24 \mathrm{hr}$. It might therefore be that binding complexes other than those involving ARE regulate MT-1 transcription at $24 \mathrm{hr}$ after reperfusion. Further studies are required to delineate the relative contributions of different promoterbinding complexes in regulating MT-1 expression after cerebral ischemia and reperfusion.

The decrease in MRE-binding activity was surprising. Radtke et al. (1993) characterized the zinc finger transcription factor MTF-1 as the major MREd-binding protein. Subsequent studies showed a role for MRE and MTF-1 in the activation of MT-1 gene expression after oxidative stress, hypoxia, and zinc accumulation (Dalton et al., 1996; Murphy et al., 1999), elements that would be expected to contribute to increased MT-1 gene expression after cerebral ischemia and reperfusion. MTF-1 and MRE may play an important role in the basal expression of MT-1, and a decreased binding 
activity of MREd may indicate a decrease in binding of the transcription factor MTF-1.

Apart from a basal binding activity of MREd and Sp1, a binding activity involving STAT3 was found in two upstream MT-1 promoter elements. This binding element has been shown recently to mediate lipopolysaccharide (LPS)-induced MT-1 transcription (Lee et al., 1999) but may also mediate basal transcriptional activity of MT-1 in brain tissue as shown in the present study. The lack of increased binding activity after cerebral ischemia and reperfusion suggests that the STAT-binding elements are not involved in MT-1 regulation in this model and that the signaling events after LPS stimulation diverge from those after ischemia and reperfusion.

MT-1 is only one of the many detoxifying (phase II) genes regulated by ARE. The list of genes containing ARE sequences is likely to grow in the near future as more genes are sequenced and their promoters analyzed (Wasserman and Fahl, 1997). To date, transcription factors that act via ARE have not been identified. Based on similarities of their binding motifs, homodimers of Maf family members and heterodimeric proteins of the Cap'n'Collar, like Nrf1 and Nrf2 (Jaiswal, 1999), are candidate factors mediating ARE responses (Igarashi et al., 1994; Blank and Andrews, 1997; Motohashi et al., 1997). Research into these and other transcription factors that could act as potent inducers of phase II enzymes via ARE may contribute to therapeutic strategies in ameliorating stroke and other acute neurodegenerative diseases.

\section{REFERENCES}

Ahlgren-Beckendorf JA, Reising AM, Schander MA, Herdler JW, Johnson JA (1999) Coordinate regulation of NAD(P)H:quinone oxidoreductase and glutathione- $S$-transferases in primary cultures of rat neurons and glia: role of the antioxidant/electrophile responsive element. Glia 25:131-142.

Akins PT, Liu PK, Hsu CY (1996) Immediate early gene expression in response to cerebral ischemia-friend or foe [review]. Stroke 27:1682-1687.

Andersen RD, Birren BW, Taplitz SJ, Herschman HR (1986) Rat metallothionein-1 structural gene and three pseudogenes, one of which contains 5' regulatory sequences. Mol Cell Biol 6:302-314.

Angel P, Imagawa M, Chiu R, Stein B, Imbra RJ, Rahmsdorf HJ, Jonat C, Herrlich P, Karin M (1987) Phorbol ester-inducible genes contain a common cis element recognized by a TPA-modulated trans-acting factor. Cell 49:729-739.

Bass NH, Hess HH, Pope A, Thalheimer C (1971) Quantitative cytoarchitectonic distribution of neurons, glia, and DNA in rat cerebral cortex. J Comp Neurol 143:481-490.

Blank V, Andrews NC (1997) The Maf transcription factors: regulators of differentiation. Trends Biochem Sci 22:437-441.

Briggs MR, Kadonaga JT, Bell SP, Tjian R (1986) Purification and biochemical characterization of the promoter-specific transcription factor, Sp1. Science 234:47-52.

Carrasco J, Hernandez J, Bluethmann H, Hidalgo J (1998) Interleukin-6 and tumor necrosis factor-alpha type 1 receptor deficient mice reveal a role of IL-6 and TNF-alpha on brain metallothionein-I and -III regulation. Mol Brain Res 57:221-234.

Carthew RW, Chodosh LA, Sharp PA (1987) The major late transcription factor binds to and activates the mouse metallothionein I promoter. Genes Dev 1:973-980.

Chan PH (1996) Role of oxidants in ischemic brain damage. Stroke 27:1124-1129.

Culotta VC, Hamer DH (1989) Fine mapping of a mouse metallothionein gene metal response element. Mol Cell Biol 9:1376-1380.

Dalton T, Palmiter RD, Andrews GK (1994) Transcriptional induction of the mouse metallothionein-I gene in hydrogen peroxide-treated Hepa cells involves a composite major late transcription factor/antioxidant response element and metal response promoter elements. Nucleic Acids Res 22:5016-5023.

Dalton TP, Lio QW, Bittel D, Liang LC, Andrews GK (1996) Oxidative stress activates metal-responsive transcription factor- 1 binding activityoccupancy in vivo of metal response elements in the metallothionein-I gene promoter. J Biol Chem 271:26233-26241.

Dignam JD, Lebovitz RM, Roeder RG (1983) Accurate transcription initiation by RNA polymerase II in a soluble extract from isolated mammalian nuclei. Nucleic Acids Res 11:1475-1489.

Du C, Hu R, Csernansky CA, Hsu CY, Choi DW (1996) Very delayed infarction after mild focal cerebral ischemia-a role for apoptosis. J Cereb Blood Flow Metab 16:195-201.
Favreau LV, Pickett CB (1995) The rat quinone reductase antioxidant response element. Identification of the nucleotide sequence required for basal and inducible activity and detection of antioxidant response element-binding proteins in hepatoma and non-hepatoma cell lines. J Biol Chem 270:24468-24474.

Igarashi K, Kataoka K, Itoh K, Hayashi N, Nishizawa M, Yamamoto M (1994) Regulation of transcription by dimerization of erythroid factor NF-E2 p45 with small Maf proteins [see comments]. Nature 367:568572.

Jaiswal AK (1994) Antioxidant responsive element. Biochem Pharmacol 48:439-444.

Jaiswal AK (1999) Nrf1 and Nrf2 regulate ARE-mediated expression and coordinated induction of a battery of genes encoding proteins that protect cells against oxidative stress. Mol Med 1172:103-112.

Kasutani K, Itoh N, Kanekiyo M, Muto N, Tanaka K (1998) Requirement for cooperative interaction of interleukin-6 responsive element type 2 and glucocorticoid responsive element in the synergistic activation of mouse metallothionein-I gene by interleukin- 6 and glucocorticoid. Toxicol Appl Pharmacol 151:143-151.

Koh JY, Suh SW, Gwag BJ, He YY, Hsu CY, Choi DW (1996) The role of zinc in selective neuronal death after transient global cerebral ischemia. Science 272:1013-1016.

Koistinaho J, Hokfelt T (1997) Altered gene expression in brain ischemia [review]. NeuroReport 8:R1-R8.

Lee DK, Carrasco J, Hidalgo J, Andrews GK (1999) Identification of a signal transducer and activator of transcription (STAT) binding site in the mouse metallothionein-I promoter involved in interleukin-6-induced gene expression. Biochem J 337:59-65.

Liu J, Kershaw WC, Klaassen CD (1991) The protective effect of metallothionein on the toxicity of various metals in rat primary hepatocyte culture. Toxicol Appl Pharmacol 107:27-34.

Liu Y, Liu J, Iszard MB, Andrews GK, Palmiter RD, Klaassen CD (1995) Transgenic mice that overexpress metallothionein-I are protected from cadmium lethality and hepatotoxicity. Toxicol Appl Pharmacol 135:222-228.

Massa SM, Swanson RA, Sharp FR (1996) The stress gene response in brain [review]. Cerebrovasc Brain Metab Rev 8:95-158.

Motohashi H, Shavit JA, Igarashi K, Yamamoto M, Engel JD (1997) The world according to Maf. Nucleic Acids Res 25:2953-2959.

Mulcahy RT, Wartman MA, Bailey HH, Gipp JJ (1997) Constitutive and beta-naphthoflavone-induced expression of the human gammaglutamylcysteine synthetase heavy subunit gene is regulated by a distal antioxidant response element/TRE sequence. J Biol Chem 272:7445-7454.

Murphy BJ, Andrews GK, Bittel D, Discher DJ, McCue J, Green CJ, Yanovsky M, Giaccia A, Sutherland RM, Laderoute KR, Webster KA (1999) Activation of metallothionein gene expression by hypoxia involves metal response elements and metal transcription factor-1. Cancer Res 59:1315-1322.

Nguyen T, Rushmore TH, Pickett CB (1994) Transcriptional regulation of a rat liver glutathione $S$-transferase Ya subunit gene. Analysis of the antioxidant response element and its activation by the phorbol ester 12-O-tetradecanoylphorbol-13-acetate. J Biol Chem 269:13656-13662.

Nishimura N, Nishimura H, Ghaffar A, Tohyama C (1992) Localization of metallothionein in the brain of rat and mouse. $\mathrm{J}$ Histochem Cytochem 40:309-315.

Palmiter RD (1998) The elusive function of metallothioneins. Proc Natl Acad Sci USA 95:8428-8430.

Pantano P, Caramia F, Bozzao L, Dieler C, von Kummer R (1999) Delayed increase in infarct volume after cerebral ischemia. Correlations with thrombolytic treatment and clinical outcome. Stroke 30:502-507.

Penkowa M, Carrasco J, Giralt M, Moos T, Hidalgo J (1999) CNS wound healing is severely depressed in metallothionein I- and II-deficient mice. J Neurosci 19:2535-2545.

Prestera T, Talalay P (1995) Electrophile and antioxidant regulation of enzymes that detoxify carcinogens. Proc Natl Acad Sci USA 92:8965-8969.

Prochaska HJ, De Long MJ, Talalay P (1985) On the mechanisms of induction of cancer-protective enzymes: a unifying proposal. Proc Natl Acad Sci USA 82:8232-8236.

Radtke F, Heuchel R, Georgiev O, Hergersberg M, Gariglio M, Dembic Z, Schaffner W (1993) Cloned transcription factor MTF-1 activates the mouse metallothionein I promoter. EMBO J 12:1355-1362.

Schoenfeld JR, Vasser M, Jhurani P, Ng P, Hunter JJ, Ross Jr J, Chien KR, Lowe DG (1998) Distinct molecular phenotypes in murine cardiac muscle development, growth, and hypertrophy. J Mol Cell Cardiol 30:2269-2280.

Thornalley PJ, Vasak M (1985) Possible role for metallothionein in protection against radiation-induced oxidative stress. Kinetics and mechanism of its reaction with superoxide and hydroxyl radicals. Biochim Biophys Acta 827:36-44.

van Lookeren Campagne MV, Thibodeaux H, van Bruggen N, Cairns B, Gerlai R, Palmer JT, Williams SP, Lowe DG (1999a) Evidence for a protective role of metallothionein-1 in focal cerebral ischemia. Proc Natl Acad Sci USA 96:12870-12875. 
van Lookeren Campagne MV, Thomas GR, Thibodeaux H, Palmer JT, Williams SP, Lowe DG, van Bruggen N (1999b) Secondary reduction in the apparent diffusion coefficient of water, increase in cerebral blood volume, and delayed neuronal death after middle cerebral artery occlusion and early reperfusion in the rat. J Cereb Blood Flow Metab 19:1354-1364.

Wasserman WW, Fahl WE (1997) Functional antioxidant responsive elements. Proc Natl Acad Sci USA 94:5361-5366.

Wegenka UM, Buschmann J, Lutticken C, Heinrich PC, Horn F (1993) Acute-phase response factor, a nuclear factor binding to acute-phase response elements, is rapidly activated by interleukin- 6 at the posttranslational level. Mol Cell Biol 13:276-288.

Westin G, Schaffner W (1988) A zinc-responsive factor interacts with a metal-regulated enhancer element (MRE) of the mouse metallothionein-I gene. EMBO J 7:3763-3770.

Wild AC, Gipp JJ, Mulcahy T (1998) Overlapping antioxidant response element and PMA response element sequences mediate basal and beta-naphthoflavone-induced expression of the human gammaglutamylcysteine synthetase catalytic subunit gene. Biochem J 332:373-381.

Xie T, Belinsky M, Xu Y, Jaiswal AK (1995) ARE- and TRE-mediated regulation of gene expression. Response to xenobiotics and antioxidants. J Biol Chem 270:6894-6900.

Yoshioka K, Deng T, Cavigelli M, Karin M (1995) Antitumor promotion by phenolic antioxidants: inhibition of AP-1 activity through induction of Fra expression. Proc Natl Acad Sci USA 92:4792-4796. 